\title{
Acute-on-chronic Liver Failure in a Young Girl
}

\author{
10.5005/jp-journals-10028-1350 \\ CPC editor \\ Pathology Discussant \\ Pathology resident \\ Clinical Discussant \\ Radiology Discussant \\ CPC chairperson \\ DOA \\ DOD \\ Date of CPC \\ : Prof Ritambhra Nada ${ }^{1}$ \\ : Dr Aravind Sekar ${ }^{2}$ \\ : Dr Kollabathula Arpitha ${ }^{3}$ \\ : Dr Arke De ${ }^{4}$ \\ : Prof Harish ${ }^{5}$ \\ : Prof Dr Kochhar ${ }^{6}$ \\ : 28-02-2019 \\ : 03-03-2019 \\ : 27-10-2019
}

An 11-year-old girl presented with progressive jaundice without cholestatic features for 2 months and progressively increasing abdominal distension for 10 days with irrelevant talk and inability to recognize parents for the last 1 day. There was a history of minor gum bleed and constipation for 3 days but no hematemesis or melena. There was no history of seizures, decreased urine output, fever or cough. There was no history of complimentary alternative medicine intake. In the past, she had Jaundice at the age of 2 years which resolved in 1 month. There was no history suggestive of autoimmune disease or liver disease in the family. She was immunized up to the age recommended by the National Immunization Scheme. She was treated with antibiotics before presentation to this institute, details of which were not available.

\section{EXAMINATION}

The child was pallor, icteric, and irritable E3V3M4; heart rate was 92 per minute; blood pressure was $128 / 80 \mathrm{~mm}$ of mercury; respiratory rate was 32 per minute; and the oxygen saturation was $92 \%$ on room air. Preabdominal examination revealed that the liver was $3 \mathrm{~cm}$ below costal margin, firm in consistency, with a span of 10 $\mathrm{cm}$; spleen was $5 \mathrm{~cm}$ below left costal margin. There was free fluid in the abdomen. Central nervous system examined GCS- $E_{3} V_{3} M_{4}$ deep tendon reflexes were brisk, Plantar's were bilateral extensor. Other systems did not reveal any abnormality.

\section{INVESTIGATIONS}

\begin{tabular}{lllll}
\hline & $\begin{array}{l}25.2 .19 \\
\text { (outside PGI) }\end{array}$ & 28.2 .19 & 1.3 .19 & 2.3 .19 \\
\hline Hb mg/dL) & 10.8 & 9.4 & 9.3 & 8.8 \\
TLC (per mm ${ }^{3}$ ) & 10,000 & 8590 & 9100 & 6350 \\
Platelets $\left(\right.$ per mm m $^{3}$ ) & 49,000 & 38,000 & 29,000 & 55,000 \\
Bilirubin (mg/dL) & $21.2 / 12.5$ & $22.7 / 10.7$ & 30.3 & \\
AST/ALT (IU) & $286 / 320$ & $37 / 190$ & & \\
ALP (IU) & 312 & 244 & & \\
INR & 4.23 & 5.08 & & \\
PT & 56 & 84.6 & & \\
aPTT & & 99.9 & & \\
Serum urea (mg/dL) & 14 & 19 & 12 & 17 \\
\hline & & & & Contd...
\end{tabular}

${ }^{1-3}$ Department of Histopathology, Postgraduate Institute of Medical Education and Research, Chandigarh, India

${ }^{4}$ Department of Hepatology, Postgraduate Institute of Medical Education and Research, Chandigarh, India

${ }^{5}$ Department of Radiology, Postgraduate Institute of Medical Education and Research, Chandigarh, India

${ }^{6}$ Department of Gastroenterology, Postgraduate Institute of Medical Education and Research, Chandigarh, India

Corresponding Author: Ritambhra Nada, Department of Histopathology, Postgraduate Institute of Medical Education and Research, Chandigarh, India, Phone: +91 7087008143, e-mail: ritamduseja@yahoo.com

How to cite this article: Nada R, Sekar A, Arpitha K, et al. Acute-on-chronic Liver Failure in a Young Girl. J Postgrad Med Edu Res 2020;54(1):20-23.

Source of support: Nil

Conflict of interest: None

Contd...

\begin{tabular}{lllll}
\hline & $\begin{array}{l}25.2 .19 \\
\text { (outside PGI) }\end{array}$ & 28.2 .19 & 1.3 .19 & 2.3 .19 \\
\hline $\begin{array}{l}\text { Serum creatinine } \\
\text { (mg/dL) }\end{array}$ & 0.48 & 0.5 & 0.5 & 0.6 \\
$\begin{array}{l}\text { Serum Na/K (meq./L) } \\
135 / 2.8\end{array}$ & $139 / 3.9$ & $40 / 4.3$ & $144 / 4.0$ \\
\hline
\end{tabular}

Arterial ammonia (28.2.19 and 1.3.19): 173 and $208 \mu \mathrm{mol} / \mathrm{L}$

Ascitic fluid: 200 cells (all polymorphs), sugar 123, protein $0.3 \mathrm{~g} / \mathrm{L}$

Procalcitonin (2.3.19): 0.47

Blood C/S (28.2.19): sterile

HBsAg: Awaited

Anti-HCV: Nonreactive

Plasma $\mathrm{Hb} / \mathrm{urine} \mathrm{Hb}$ : 96/nil

DCT: Negative

Serum ceruloplasmin: Awaited

Autoimmune work-up: Awaited

USG abdomen (28.2.19): Liver, shrunken with heterogenous echotexture and multilobulated outline; spleen, $15 \mathrm{~cm}$; PV, $9.5 \mathrm{~mm}$ at porta; GB, diffuse wall edema; moderate ascites and $B / L$ pleural effusion; $B / L$ kidneys, normal

\section{Course and Management}

An 11-year-old developmentally normal, immunized for age girl, presented with a history of jaundice for 2 months, abdominal

() The Author(s). 2020 Open Access This article is distributed under the terms of the Creative Commons Attribution 4.0 International License (https://creativecommons. org/licenses/by-nc/4.0/), which permits unrestricted use, distribution, and non-commercial reproduction in any medium, provided you give appropriate credit to the original author(s) and the source, provide a link to the Creative Commons license, and indicate if changes were made. The Creative Commons Public Domain Dedication waiver (http://creativecommons.org/publicdomain/zero/1.0/) applies to the data made available in this article, unless otherwise stated. 
distension for 10 days, and altered sensorium for 1 day. O/E she had pallor, icterus, asterixis, hepatosplenomegaly and free fluid per abdomen. Possibility of acute on chronic liver failure (ACLF) vs acute liver failure (ALF) was kept. In view of signs of raised intracranial tension (ICT), she was started on intracranial pressure (ICP) lowering and anti-hepatic encephalopathy (HE) measures including $3 \%$ saline, lactulose and rifaximin. She was intubated at 18 hours of admission in view of poor Glasgow coma scale. In view of deranged coagulogram with gum bleed, fresh frozen plasma was transfused. She had a worsening respiratory failure with profuse bleed from the endotrachial tube. X-ray of the chest showed bilateral diffuse homogeneous opacities possibly due to pulmonary hemorrhage. She suffered cardiorespiratory arrest on day 3 of hospital stay. Cardiopulmonary resuscitation was done according to the protocol but she could not be revived.

- Units diagnosis ALFACLF

- Hepatic encephalopathy, ascites, coagulopathy

- Pulmonary hemorrhage

\section{Case Description}

In this 11-year-old developmentally normal, immunized for age girl with a history of self-limiting jaundice at 2 years of age now presented with non-cholestatic, progressive jaundice 2 months with thrombocytopenia, mixed hyperbilirubinemia, transaminitis 6-8x upper limit of normal, hypoalbuminemia, coagulopathy, shrunken liver with splenomegaly, low protein ascites ( 10 days) with spontaneous bacterial peritonitis and altered sensorium since 1 day.

With this background the child falls into which syndromic diagnosis?

Following are the definitions of each syndromic diagnosis:

\section{Acute Liver Failure}

Jaundice with coagulopathy (INR >1.5) and any degree of encephalopathy within 26 weeks without preexisting liver disease (exceptions: Wilsons, AlH, BCS, vertically acquired CHB).

\section{Acute-on-chronic Liver Failure}

laundice (serum bilirubin $>5 \mathrm{mg} / \mathrm{dL}$ ) and coagulopathy (INR>1.5) complicated within 4 weeks by clinical ascites and/or encephalopathy with previously diagnosed or undiagnosed chronic liver disease/cirrhosis.

\section{Subacute Hepatic Failure}

Progressive or persistent jaundice with unequivocal ascites developing $>4$ weeks after onset of jaundice with evidence of ongoing necrosis; baseline liver normal.

The index case will fall in ACLF $>>$ SAHF $>>$ ALF (subacute type).

Because of the typical presentation of jaundice followed by ascites and/or HE, with shrunken liver, splenomegaly, thrombocytopenia will favor more ACLF than others.

The etiology that favors ACLF is

- Acute: acute viral hepatitis, flare of underlying chronic disease

- Chronic: autoimmune hepatitis, Wilsons

SAHF is acute viral hepatitis, autoimmune hepatitis

Acute liver failure is acute viral hepatitis, autoimmune hepatitis, Wilsons

According to the Indian data of pediatric ALF, the commonest etiology is viral infections followed by metabolic liver diseases and drug induced liver injury.
In pediatric $\mathrm{ACLF}$, Wilsons and $\mathrm{AlH}$ are the commonest chronic etiologies while acute viral hepatitis is the commonest precipitating event.

For SAHF limited data was available, commonest etiology is acute viral hepatitis (HEV and HAV) followed by autoimmune hepatitis and drug-induced liver injury (DILI).

\section{Final Diagnosis}

- ACLF (SAHF, subacute ALF)

- Acute

- Acute viral hepatitis (HEV)

- Flare of AlH/Wilsons

- Chronic

- AlH

- Wilsons

- Ascites, hepatic encephalopathy, coagulopathy

- SBP

Cause of death: pulmonary hemorrhage

\section{Clinical Discussion}

Chairperson (Prof Rakesh Kochhar): Thank you Arke. Nicely elaborated the case. Please join me here. Now case is open for comments and opinion.

ProfDr RK Dhiman: Clinical presentation of this case is more like ACLF and meets current criteria for the same. Patient had some history of jaundice at 2 years and recovered, indicating some underlying liver disease from 2 years of age and now present with acute manifestation. The possibilities of Wilson and autoimmune are considered in this setting as discussed by Dr Arke. Whatever may be, at present this patient has to be managed as per ALF protocol.

ProfDr Usha Dutta: I also go with possibilities of Wilson and autoimmune hepatitis. If we have serum markers, it would have helped in sorting out the differential diagnosis.

ProfDr Virender Singh: The clinical picture is not matching the criteria for ACLF. Definitely we are dealing with some chronic liver disease.

ProfDr Sanjay: In ultrasound, it was mentioned as shrunken liver and on clinical examination, liver was palpable. There was some clinic radiological discorrelation. Is it really chronic?

Chairperson (Prof Rakesh Kochhar): Various opinion from the house. We will see what will be there in autopsy. May I request $\mathrm{Dr}$ Aravind to show autopsy findings.

\section{Pathology Findings (PM)}

A partial autopsy was performed. The prosecutors noted the peritoneal cavity was filled with a straw color fluid and yielded 250 $\mathrm{mL}$ of fluid. The pleural and peritoneal fluids were within normal limits.

Liver: Weigh 365 g; capsule was wrinkled and relatively shrunken; firm in consistency; cut surface showed irregular pale to tan colored areas of variable size alternating with greenish yellow nodules of variable size. Few nodules are seen on the surface measuring $3.5 \mathrm{~cm}$ in maximum dimension. Biliary tract did not show structural abnormality. Portal vein did not show any thrombus Figures $1 \mathrm{~A}$ and $\mathrm{B}$.

Microscopic examinations revealed large areas of necrosis with preserved islands of hepatocytes in-between. Necrosis was pan lobular and nonzonal in distribution. Most of the portal tract 

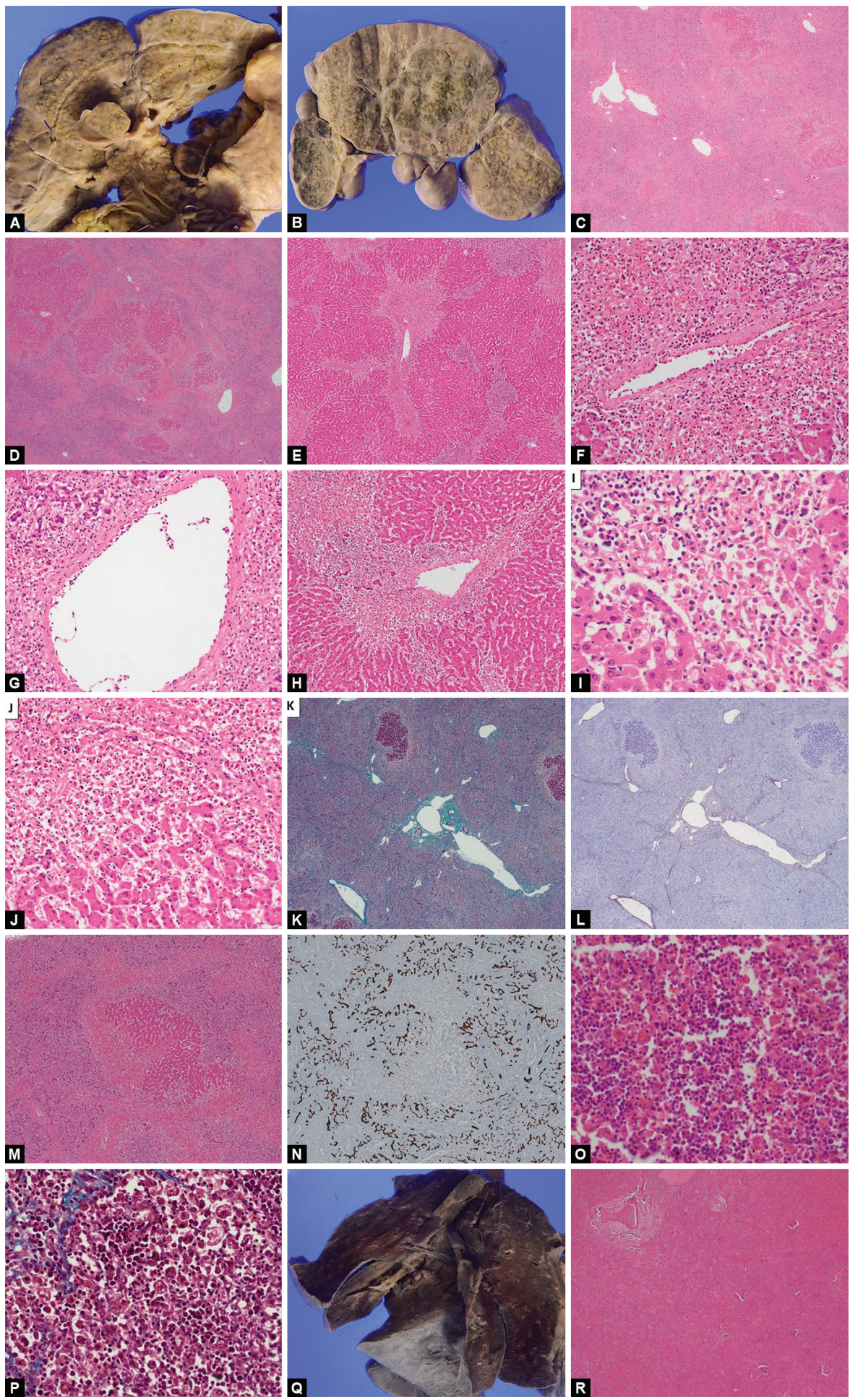

Figs $1 A$ to R: (A and B) Cut surface of liver shows irregular pale to tan colored areas of variable size alternating with greenish yellow nodules of variable size. Few nodules are seen on the inferior surface measuring $3.5 \mathrm{~cm}$ in the maximal dimension (gross photograph); (C and D) Multiacinar panlobular necrosis with preserved island of hepatocytes (100X, microphotograph, H\&E); (E) Centrizonal necrosis with loss of hepatocyte around central venule (200x, microphotograph, H\&E); $(F$ and $G)$ Central venulitis with lifting of endothelial cells by inflammatory cells (400X, microphotograph, $\mathrm{H \& E}) ;(\mathrm{H}$ and I) Moderate lymphoplasmacytic inflammatory cell infiltrate in portal tracts with interface hepatitis rich in plasma cells (200X and 400X, microphotograph, H\&E); (J) Few hepatocytes in periportal region show emperipolesis (200x, microphotograph, H\&E); (K and L) Masson trichrome and orcein stain highlight portal tract fibrosis with extension of fibrous septae into hepatic lobules and few portoportal bridging fibrosis indicating chronicity (200x, microphotograph); (M and N) Extensive bile ductular proliferation seen adjacent to necrosis (200x, microphotograph, H\&E and CK 7 immunostaining); ( $O$ and P) Microphotographs of lymph node show increase in number of histiocytes with hemophagocytosis (200×, microphotograph, H\&E and MT); ( $Q$ and R) Cut surface of lungs shows hemorrhagic consolidation and corresponding section shows hemorrhage in alveolar spaces $(100 \times$, microphotograph, H\&E) 
showed moderate lymphomononuclear cell inflammation rich in plasma cells. Porto-portal and occasional Porto-central fibrosis was seen on orcein stain. However, no cirrhotic nodules were present. Significant interface hepatitis was seen. Emperipolesis and hepatocyte rosettes were also present. Both central vein and portal vein showed venulitis. Extensive bile ductular proliferation was noted highlighted by CK7 stain. No significant cholestasis or steatosis was present. No storage cells were seen. Rhodamine stain did not highlight any copper deposits Figures $1 \mathrm{C}$ to $\mathrm{N}$.

Spleen: Weight $273 \mathrm{~g}$, enlarged and congested. Sections examined showed expansion of red pulp with capillarization of sinusoids. Focally hemophagolymphohistiocytois was seen.

Lymph nodes were enlarged in peripancreatic region and para-aortic region and on microscopy showed reactive germinal center with prominence of histiocytes with hemophagolymhohistiocytosis Figures 10 and $\mathrm{P}$.

Kidneys: weight $245 \mathrm{~g}$; cut surface was unremarkable. On microscopy, all four compartments did not show any diagnostic change.

Heart: Weight $157 \mathrm{~g}$; both grossly and microscopically unremarkable.

GIT: GE junction showed dilated veins both in lamina propria and submucosal layer.

Small intestine and large intestine were grossly and microscopically normal.

Lungs: Weight $768 \mathrm{~g}$. Pleuron was dull. Pleural tags were seen. Cut surface was consolidated to feel and showed hemorrhages in all the lobes of right and left lung. On microscopy, alveolar spaces were filled with hemorrhage. Fibrin was noted along alveolar ducts and respiratory bronchioles Figures $1 \mathrm{Q}$ and $\mathrm{R}$.

Adrenals, thyroid, skin, uterus, ovaries, and skeletal muscle did not reveal any significant pathological findings.

Bone marrow showed mildly hypocellular marrow with evidence of hemophagocytosis.

Final Autopsy Diagnosis (PM 29377): A 11-year-old girl who presented with ACLF.

- Massive panlobular centrizonal hemorrhagic necrosis with chronic hepatitis (Score 4) (typical of acute exacerbation of chronic autoimmune hepatitis).

- Portal hypertension: ascites, splenomegaly and esophageal varices.
- Hemophagolymphohisticytosis in lymph nodes, spleen and bone marrow.

- Pulmonary hemorrhages.

\section{Final Discussion}

Prof Rakesh Kochhar: Thank you, Dr Aravind. Please join me here. Prof Dr RK Dhiman: I think Dr Arke has microscopic eyes, he analysed the diagnosis exactly.

Prof Ashim Das: This is a classical finding of acute exacerbation of chronic autoimmune hepatitis. Massive multiacinar, pan lobular necrosis along with predominant centrizonal necrosis is described in autoimmune hepatitis. Central venulitis with lifting up of endothelial cells as shown is typically described in autoimmune hepatitis.

Prof Dr Sadhana Lal: Extensive Liver progenitor cells mediated bile ductular proliferation seen in response to massive hepatic necrosis would result in regenerative nodule but cannot compensate the loss.

Dr Aravind: Probably these regenerative nodules might me the reason for palpable liver on examination although shrunken liver was described on ultrasonogram.

Prof Dr Usha Dutta: Massive hepatic necrosis is shown in autopsy. Is there any chronicity?

Prof Dr Ashim Das: Yes, there are fibrous septae with extension into hepatic lobule with porto-portal and occasional portal central bridging fibrosis. Definitively there is chronicity.

Prof Rakesh Kochhar: Thank you all. We had a good clinicopathological case discussion and demonstration of acute exacerbation of autoimmune hepatitis today.

\section{References}

1. Rahim MN, Liberal R, Miquel R, et al. Acute severe autoimmune hepatitis: corticosteroids or liver transplantation? Liver Transpl 2019;25(6):946-959. DOI: 10.1002/lt.25451.

2. Balitzer D, Shafizadeh N, Peters MG, et al. Autoimmune hepatitis: review of histologic features included in the simplified criteria proposed by the international autoimmune hepatitis group and proposal for new histologic criteria. Mod Pathol Off J U S Can Acad Pathol Inc 2017;30(5):773-783. DOI: 10.1038/modpathol.2016.267.

3. Kirsch R, Yap J, Roberts EA, et al. Clinicopathologic spectrum of massive and submassive hepatic necrosis in infants and children. Hum Pathol 2009;40(4):516-526. DOI: 10.1016/j.humpath.2008.07.018. 